\title{
Cuerpos tatuados, "Almas" TAtuadas: \\ nuevas formas de subjetividad en la contemporaneidad
}

\author{
ANDREa LisSETt PÉREZ Fonseca \\ Profesora de la Universidad de Antioquia. Doctora y maestra en Antropología \\ Social de la Universidad Federal de Santa Catarina, Brasil. Pregrado en Antro- \\ pOLOGía DE LA UNIVERSidAd NACIONAL DE COLOMBia. \\ andreaperez7I@hotmail.com
}

\begin{abstract}
Resumen
[STE ARTÍ́CULO HACE UNA DESCRIPCIÓN ETNOGRÁFICA CONTEMPORÁNEA DEL TATUAJE, DESDE UNA -perspectiva conceptual que prioriza el sentido de práctica, de las interacciones y de las experiencias vividas durante el proceso de tatuarse. Esta reflexión intenta reconstruir una visión holística del tatuaje que abarca el mundo subjetivo de los actores, así como la dinámica social que hace parte de ese acto. Las principales conclusiones son: El surgimiento de una nueva "normalidad" estética y vivencial en el seno de la sociedad Occidental y la configuración de la nueva subjetividad de los "tatuados", entendida como un proceso interactivo, innovador, emotivo y reflexivo, en el que el cuerpo se convierte en forma de expresión y construcción del sujeto.

PALABRAS Clave: tatuaje, cuerpo, subjetividad, individualidad.
\end{abstract}

\section{TAtToed bodies, TAtToed "SOuls". NeW FORMS OF SUBJECTIVITY IN THE CONTEMPORARY WORLD}

\begin{abstract}
THIS ARTICLE PRESENTS AN ETHNOGRAPHIC DESCRIPTION OF THE CONTEMPORARY TATTOOING PRACTICES from a conceptual perspective that prioritizes it's meaning, the interactions and the lived experiences while being tattooed. This reflection attempts to reconstruct a holistic practice of tattoo that comprises the subjective world of actors as well as the related social dynamics. The main conclusions are: The emergence of a new aesthetic and lived "normalcy" at the heart of Western society and the configuration of a new subjectivity of those who are tattooed, as an interactive, innovative, emotional and reflexive process in which the body turns into a form of expression and a construction of the subject.
\end{abstract}

KEY WORDS: tattoo, body, subjectivity, individuality.

\section{Revista Colombiana de Antropología}

Volumen 45 (I), enero-junio 2009, pp. 69-94 


\section{INTRODUCCIÓN}

L

L TATUAJE EN LA CONTEMPORANEIDAD HA ADQUIRIDO NUEVAS FORMAS de uso y valores sociales. Dejó de ser una práctica exclusiva - de la marginalidad, tal como se le reconocía durante el siglo XIX y buena parte del siglo XX y hoy es cada vez más frecuente ver cuerpos tatuados entre los distintos sectores sociales, sin restricciones (o muy pocas) de género, de edad o de estatus. El tatuaje incursionó en nuevos contextos sociales y adquirió nuevos significados. ¿Cómo se produjo este cambio? ¿Por qué ahora es posible pensarlo como adorno corporal y obra artística? ¿Qué nuevos sentidos fueron reconstruidos? Pese a que este fenómeno es objeto de indagación de las ciencias sociales, los análisis existentes tienden a centralizarse en aspectos parciales, priorizando la perspectiva de los tatuadores, la de los tatuados o del mismo tatuaje como foco de disertación (Gougel, 200I; Falk, I995; Grognard, 1992; Le Breton, I995, 2002; Pierrat, 2000; Sanders, I998; Sweetman, I999). Se carece de una visión más holística que intente contemplar las distintas dimensiones que constituyen este nuevo contexto o parafraseando a Marcel Mauss (I99I), de una perspectiva de "hecho social total" que ayude a comprender el proceso en su complejidad y en sus singularidades. El propósito de este artículo es contribuir con una visión "total" del tatuaje, a partir de la noción de práctica, entendida como un "nuevo orden de pensamiento en la antropología". En efecto, como plantea Ortner (I984), desde los años 8o la antropología ha hecho de la práctica un símbolo clave al cual se le relaciona una serie de conceptos que configuran una nueva lectura de lo social. Así, conceptos como praxis, experiencia, vivencia e interacción engloban el sentido directo de la práctica y permiten pensar la vida social en movimiento y en acción. Bastante próximos a estos conceptos están las nociones de sujeto, persona, self, actor y agente, que ocupan un lugar privilegiado en esta nueva visión teórica, como hacedores y protagonistas de la acción social. En consecuencia, el mundo social, al ser analizado desde el enfoque de la práctica, deja de ser visto

I. Concomitante con este marco conceptual, uso en el análisis aportes teóricos como los de Víctor Turner (1987) para pensar el sentido de proceso, experiencia, cambio y ritualidad y de Erving Goffman (I985) en la reflexión sobre las interacciones sociales y el problema del estigma social. como una estructura de normas en la que los individuos son incorporados, y empieza a ser pensado como un mundo construido por sujetos activos. ${ }^{1}$ 
Volumen 45 (I), enero-junio 2009

Los argumentos que sustentan este artículo provienen de un estudio etnográfico realizado entre junio de 2002 y mayo de 2003 en una de las tiendas de tatuaje más modernas de la ciudad de Florianópolis (Brasil): Experience Art Tattoo, abierta al público desde el año de 1996, y localizada en el centro de la ciudad. El trabajo de campo se desarrolló en cuatro fases. La primera, de aproximación e inserción, fue facilitada por el uso de la fotografía, que en este medio posee especial valor ya que la mayoría de usuarios del tatuaje demuestran interés por la imagen y la exhibición de sus tatuajes. En este caso la cámara fotográfica funcionó como excelente mediadora de las relaciones interpersonales. ${ }^{2}$ La segunda fase estuvo marcada por mi participación, junto a los dueños de la tienda de tatuaje y varios amigos en la VII Convención Internacional de Tatuaje (octubre de 2002 en Sao Paulo), experiencia intensa, no sólo por vivir de cerca el selecto mundo del tatuaje en una atmósfera cargada de simbolismo, de performances y de exaltaciones de la corporalidad, sino también por la convivencia y proximidad ganada con el grupo de la tienda investigada, que ayudó a legitimar mi presencia en el campo etnográfico. Durante la tercera fase, de acompañamiento a las actividades cotidianas del estudio de tatuaje, conté con la ventaja de ser tratada como "amiga de la casa”, condición que me permitió actuar con más espontaneidad y sostener conversaciones informales con mayores niveles de confianza e intimidad. Por último, además de profundizar en el proceso de observación en la tienda, realicé entrevistas focalizadas con el fin de reconstruir trayectorias de vida referidas a la práctica del tatuaje. ${ }^{3}$

\begin{abstract}
2. Mi interés inicial en esta temática estuvo motivado por la antropología visual y la aplicación de la fotografía etnográfica, proceso en el que estuve acompañada de la fotógrafa y amiga Christiane Ott Mayer con quien realizamos un archivo de cerca de 500 fotografías y hemos participado en algunas muestras de fotografía etnográfica.

3. A lo largo del artículo se utilizarán informaciones verbales provenientes de este universo social investigado. La muestra de informantes seleccionada son: Mano, el tatuador, Gesa, encargada de la atención al público, algunos clientes ocasionales (Marcelo), así como las voces de seis personas que están en la dinámica de "encerramiento corporal": Sampaio, Fabricio, Adriano, André, Silvana y Luciana. Intenté escoger personas diversas en cuanto a edad, sexo, actividades y porcentajes del cuerpo tatuado, para tener una panorámica más amplia del fenómeno estudiado; elementos que serán indicados en el momento de la citación.
\end{abstract}

A pesar de que el propósito del artículo es presentar la mayor cantidad de elementos etnográficos que ayuden a dar una visión "total" de esta práctica, debo reconocer que el proceso de investigación me impuso algunos recortes. Por eso, a pesar de haber identificado varios estilos de uso y apropiación del tatuaje, tales 
como los "de detalle", que usan tatuajes pequeños y discretos, o los "radicales", que tatúan todo su cuerpo, inclusive en aquellas partes consideradas tabú como el rostro y las manos, la presente reflexión se centrará en el grupo de los "tatuados", término con el que ellos mismos se reconocen. Estos son individuos que se encuentran en un proceso de "encerramiento de sus cuerpos con tatuajes" pero que, a diferencia de los "radicales", no transgreden los límites sociales. Así, la etnografía y las aproximaciones conceptuales estarán remitidas a este grupo de personas que presenta características interesantes para la comprensión de procesos de construcción de subjetividad en la contemporaneidad, mediante prácticas corporales como el tatuaje.

\section{El tatuaje en OCCIDENTE}

L DESCUbrimiento del tatuaje en Occidente está vinculado a las - grandes expediciones marítimas del siglo XVIII, en especial a - las Islas del Pacífico donde se encontró que el tatuaje era una práctica expandida entre los nativos y cumplía importantes funciones sociales (Grognard, I992: 22). Varios capitanes y marineros se comenzaron a interesar por este arte, al tatuarse y transformar así sus propios cuerpos en una tela de exhibición. A pesar de que ya se tenía conocimiento de diferentes marcas corporales existentes entre los llamados pueblos "primitivos", sólo cuando los marineros y viajeros tallaron sus propias pieles se empezó a establecer un puente entre el tatuaje y Occidente. Así, el contexto social con el que se reinicia esta práctica en Occidente estuvo marcado por el contacto con otras culturas, distantes y diferentes, cuyas expresiones estéticas y culturales, tales como el tatuaje, eran vistas como "exóticas".

Después, durante el siglo XIX y comienzos del XX, el tatuaje siguió una fase de peregrinación por los sectores marginales de la sociedad, donde presidiarios, meretrices y soldados se convierten en los nuevos protagonistas de esa práctica; los ambientes por donde empieza a circular el tatuaje son las penitenciarias, los cuarteles y la calle. En la cárcel el tatuaje cobró una significativa 
Volumen 45 (I), enero-junio 2009

importancia, al punto de ser conocido popularmente como la "flor del presidio" (Grognard, I992: 25). Al convertirse en objeto de preferencia de esos sectores sociales, el tatuaje se situó en las "márgenes" de la sociedad, situación que generó una construcción negativa en torno de esa práctica, que extendió y validó un sentido de referencia-equivalencia del tatuaje como marca de marginalidad (Le Breton, 2002: 6I). Imaginario que fue apropiado por distintos grupos y tribus urbanas, como los teddy boys, bikers o los Hell's Angels en los años 60 o los punk y los skins en los años 70, quienes utilizaron el tatuaje como marca corporal a través de la que ostentaban en público su deseo de romper con las reglas sociales y de situarse deliberadamente en las márgenes de su propia sociedad (Pierrat, 2000).

Un hecho aparentemente banal pero fundamental en el desarrollo del tatuaje en Occidente es la invención de la máquina eléctrica a finales del siglo XIX, ya que cambió el rostro de esta práctica, al revolucionar aspectos claves como la reducción de tiempo del trabajo y la cualificación técnica en la aplicación de los tatuajes. Con consecuencias en la parte técnica, esta máquina afecta las condiciones sociales de elaboración dada la necesidad de contar con un punto de corriente eléctrica, con lo que fija el ejercicio y con ella al tatuador, quien debía dedicar más tiempo para ese oficio. Así, se inicia lo que Pierrat (2000) denomina la "profesionalización del tatuaje", con un saber más tecnificado y una mayor especialización de sus oficiantes. Ese proceso da lugar a una nueva configuración del escenario del tatuaje, en especial en ciudades de Estados Unidos y Canadá, donde inicialmente funcionaron pequeños estudios dentro de barberías o casas de billar, que con el paso del tiempo se independizaron (Pierrat, 2000: 210). No obstante, la verdadera eclosión del tatuaje y su propagación en el mundo occidental ocurre en la década de 1980 cuando se abren modernos locales de tatuaje dotados de equipos especializados, materiales desechables y diferentes medios de promoción, que responden a nuevas demandas y formas de concepción del cuerpo abiertas a la experimentación y a las transformaciones corporales (Le Breton, 2002). El tatuaje se convierte entonces en una opción estética y vivencial ensayada por las nuevas generaciones. 
Cuerpos tatuados, "almas" tatuadas: Nuevas formas de subjetividad en la contemporaneidad

\section{Nuevos escenarios: El tatuaje en Brasil}

L

L PROCESO DE MODERNIZACIÓN DEL TATUAJE EN BRASIL SIGUE UN CAMINO más lento debido a la dificultad de acceso a las nuevas técnicas y, principalmente, a la máquina eléctrica. Su desarrollo dependió de la mediación realizada por tatuadores extranjeros, portadores de los nuevos saberes y tecnología de este arte, como es el caso del conocido Tattoo Lucky, marinero danés de familia de tatuadores, que llegó al Brasil en 1959 y se radicó allí hasta su muerte en I983 y quien se convirtió en el "mito de origen" del tatuaje contemporáneo brasilero (Marques, 1997: 175). Su prestigio radicaba en el dominio que tenía de la técnica moderna en un momento en que el tatuaje aún era realizado a mano. Lucky ejerció una influencia importante en la generación de los "modernos" tatuadores brasileros (Stopa, Tuca, Alemão), que tuvieron con él su primera escuela de aprendizaje. Durante las décadas del 70-80 en Brasil se vivió un periodo de experimentación, de transición de las "agujas caseras" a la fabricación de las máquinas eléctricas: "Entró en acción la inventiva brasilera. Grabadoras, vitrolas, aparatos de barbería y aceleradores de pista de juguetes fueron sacrificados en nombre del arte" (Marques, 1997: 192). El tatuaje se practicaba en lugares improvisados, por lo general, en casa de los tatuadores, manteniéndose así como un oficio artesanal y en un ambiente en el que predominaban las relaciones de amistad y de festividad: "Se tatuaba en un clima de fiesta; la persona llegaba en la mañana y salía en la madrugada, borracho y tatuado" (Gesa, 33 años, dueña de la tienda, 2002). Ese escenario comienza a transformarse en los años 90 con la apertura de los estudios especializados que promueven una nueva imagen de esa práctica al resaltar valores como el "profesionalismo", la "calidad artística" y los "cuidados higiénicos".

Este último es el contexto que caracteriza la tienda de tatuaje Experience Art Tattoo, objeto de nuestra investigación desde su apertura en 1996. Localizada en una casa antigua de estilo portugués, se destaca porque en su fachada sobresalen grandes máscaras carnavalescas que atraen la atención del público. En su interior, la primera sala funciona como área de atención al público y las paredes están decoradas con íconos típicos de la tradición del tatuaje, como rostros tatuados, figuras lúdicas, eróticas y diabólicas, así como algunas imágenes surrealistas diseñadas por el tatuador del lugar. Mientras la segunda sala, el 
Volumen 45 (I), enero-junio 2009

estudio de tatuaje, se caracteriza por la blancura, la austeridad de objetos y la presencia de muebles clínicos. Anexa está la sala de esterilización, dotada con el equipo e instrumentos necesarios para ese fin. La tienda está construida sobre un bricolaje de símbolos entre los que se pueden destacar los que realzan el "exotismo" típico de los inicios de esta práctica en Occidente, y aquellos relacionados con el ambiente clínico (lo blanco, la simpleza del mobiliario), en un estilo conceptualizado por sus creadores como clean con el que buscan: "Que las personas de mayor edad y de una clase social y cultural más sobresaliente acaben con esa historia del preconcepto del tatuaje” (Gesa, 2002). En efecto, existe una intención clara de acceder a públicos distintos, en particular a aquellos que cuentan con más recursos para pagar el costo de un servicio cada vez más sofisticado. Con ese objetivo recurren, siguiendo a Goffman (I985), a una alteración simbólica de la fachada social:

Por más especializada y singular que sea una práctica, su fachada social tenderá a reivindicar hechos que pueden ser igualmente reivindicados y defendidos por otras prácticas algo diferentes [...] Mientras, de hecho, esos padrones abstractos tengan un significado diferente en diferentes desempeños de servicios, el observador es conducido a realzar las semejanzas abstractas" (Goffman, I985: 33).

La alteración de la fachada del tatuaje está mediada por la incorporación de elementos típicos del ambiente clínico que recrean, de forma abstracta, una correlación entre esos dos espacios. Aunque abstracta, tal semejanza está cargada de significado porque lleva al campo simbólico, lo que identifica al ambiente clínico y las percepciones asociadas tales como limpieza, confianza, tranquilidad y seguridad. De igual forma, se intenta modificar el estatus del tatuador mismo de aficionado a profesional y artista. Sin embargo, esa transformación no es fácil debido a la larga historia de desprestigio y estigmatización del tatuaje que se evidencia en la serie de valores negativos con los que se asocia: sucio, peligroso, prohibido y contaminado. Esos apelativos, recurrentes tanto en la literatura revisada como en los testimonios recogidos, hacen pensar que el tatuaje y su universo aún se asocian simbólicamente del lado de lo "impuro". En esa perspectiva, el análisis desarrollado por Mary Douglas (I973) sobre la dicotomía pureza-impureza como ordenadora simbólica de la realidad, puede ser esclarecedor de esta clasificación: 
[...] Ciertos valores morales se sostienen, y ciertas reglas sociales se definen, gracias a las creencias en el contagio peligroso [...] las creencias de contaminación pueden usarse en el diálogo de reivindicaciones y contra-reivindicaciones de una categoría social [...] las ideas de contaminación se relacionan con la vida social. Creo que algunas contaminaciones se emplean como analogías para expresar una visión general del orden social” (Douglas, I973: 16).

La asociación entre tatuaje y suciedad puede ser vista entonces como una forma social de reacción frente a una situación considerada peligrosa, provocadora de desorden y generadora de un tipo de "anormalidad". Pero, ¿cuál es ese orden o normalidad que el tatuaje transgrede? La "normalidad" del cuerpo al modificarse viola su estado "natural". Alterar el cuerpo es generar un desequilibrio en el orden de las cosas, que en Occidente continua regido por el pensamiento religioso de origen judeo-cristiano y en el que toda modificación corporal se concibe como una profanación del cuerpo y de la imagen de Dios (Falk, 1995). De ese modo, el tatuaje es encasillado en la categoría de lo "impuro" y asociado con todos los valores negativos que evoca, pues se relaciona con el estilo de vida que históricamente ha hecho parte de los limbos sociales, la marginalidad, la rebeldía y la transgresión. Todo esto delimita un perfil de desvío social e inclusive de enfermedad mental (Sanders, 1987). Mientras los usuarios restringían su tránsito por esos universos sociales no había mayores contradicciones con la forma como se asumía socialmente el tatuaje, pero al intentar salir de esas fronteras, tal como lo manifiestan los nuevos actores, se genera una intensa lucha en el campo de lo simbólico por cambiar ese rostro y ganar un nuevo espacio social.

\section{LA EXPERIENCIA DE TATUARSE: \\ INTERACCIÓN Y RITUALIDAD}

N NUESTRO INTERÉS PARA DAR CUENTA DEL PROCESO, LAS EXPERIENCIAS Y
los Contactos interpersonales que constituyen y dan sentido al
acto de tatuarse, el primer elemento a destacar es la selección
de la tienda de tatuaje por parte del individuo. Aunque no lo
parezca, escoger un lugar no es tan simple porque prevalecen
una serie de miedos, tales como el contagio de enfermedades por 
Volumen 45 (I), enero-junio 2009

vía sanguínea (sida), el dolor y la desconfianza hacia el tatuador. Por eso son de vital importancia el impacto positivo que genere el escenario y la oferta de este servicio dentro de los nuevos cánones comerciales: cuidado higiénico, calidad técnica y artística del tatuaje. Al realizar la elección, la persona ha establecido vínculos mínimos de confianza y empatía frente al lugar, fundamentales para iniciar el acercamiento a los actores de ese espacio y en especial al tatuador. De hecho, tras las interacciones y pequeñas negociaciones asociadas con esta relación comercial se empiezan a formar lazos de proximidad. Esto es claro en el momento de definir el diseño pues la mayoría de personas que van a tatuarse no han decidido en realidad qué quieren hacerse:

-La mayoría de personas vienen jurando que quieren aquello, pero en el momento que comienzas a trabajar la imagen, todo cambia. Comienzan las dudas: "Pero esto fue fulano de tal que me indicó y yo no quería eso así”. Ahí captas que la persona está con miedo, insegura o realmente no sabe lo que quiere. Entonces comienzas a trabajar con la idea de la persona” (Mano, 34 años, tatuador, 2002).

En este momento se genera una interacción significativa que podría identificarse como la captura de las ideas y que consiste en la concreción de las que trae la persona mediante el diálogo reflexivo con el tatuador. Para este último, las ideas de la persona se refieren a la psiquis de la persona, su mundo interno y sus gustos personales. Cuando el tatuador dice "trabajar con las ideas de la persona", denota una búsqueda en el mundo interno del sujeto de un algo con el que se identifique y, en esa medida, adquiera el valor de ser inscrito y eternizado en su cuerpo. Por tanto la imagen, como representación de la "idea", es relevante no tanto por su contenido, sino por lo que ella es capaz de decir algo del sujeto, de revelar algo acerca de su interioridad; al igual que el tatuador, juega un papel relevante como mediador de esa subjetividad, exteriorizada en la iconografía del tatuaje.

Ejemplo de esta negociación es el caso de Marcelo, músico de 30 años de edad quien decidió hacerse su primer tatuaje y como la mayoría de personas no tenía definido el diseño; sólo sabía que quería algo relacionado con la música. La interacción con el tatuador fue bastante informal, hablaron de diversos temas, revisaron catálogos, analizaron varias opciones, hasta que el tatuador sugirió los ideogramas chinos como forma simbólica de representar las virtudes de la música. A Marcelo le gustó la idea 
y comenzó a pensar en las figuras, su tamaño y la forma como quedarían en su cuerpo. Optó por los ideogramas de la sabiduría, la protección y la justicia, y cuando le pregunté por su significado respondió seguro: "Ahí está la música en el sentido espiritual". Con respecto a los tamaños de los tatuajes hubo una pequeña diferencia, pues Marcelo creía que los ideogramas debían ser

4. La prueba es una imitación de la forma, el tamaño y la localización del tatuaje en el cuerpo. Ese procedimiento varía según el tatuaje. Si es "comercial", o sea cuando está definido en algún material impreso, sólo se requiere calcarlo en la piel. Pero si es de "creación", el tatuador debe realizar un diseño experimental sobre la piel, basándose en las "ideas" discutidas con el cliente. más pequeños y el tatuador, más grandes. Marcelo no parecía estar convencido del todo, así que decidieron hacer una "prueba"4 sobre el cuerpo, después de la cual Marcelo optó por el tamaño sugerido por Mano.

Una vez definido el tatuaje se llega a la última fase del proceso: tatuarse. Este es el momento esperado que materializa un proyecto personal y en el que la relación con el tatuador adquiere más intensidad, dadas las distintas facetas que entran en juego: la piel, la sangre, el dolor, en fin, todo lo que implica la interferencia en el cuerpo. Es una relación demarcada por la simpatía entre las partes (Le Breton, 2002:90), que va mucho más allá de lo estrictamente profesional y comporta niveles de intimidad: "Generalmente, la persona que usted tatúa se vuelve amiga, porque es algo que usted va a dejar para siempre en su piel, es una cuestión de sentimiento, hasta de espiritualidad, es la sangre que está corriendo [...] (Mano, 2003).

El ambiente donde tiene lugar este acto es el estudio de tatuaje que, como ya se mencionó, se destaca por un aspecto clínico que refuerza el sentimiento de seguridad en y del lugar. Todo luce limpio, en tonos blancos y forrado en papel desechable, sobre todo aquellas partes que entran en contacto durante la aplicación del tatuaje. El tatuador, revestido de una imagen de autoridad, que porta una mascarilla y guantes quirúrgicos asume postura de "profesional" que inspira respeto. Por su parte, el sujeto que va a tatuarse, recostado en la silla, está a la expectativa, en una actitud de disposición: de dejar su cuerpo bajo el control del "especialista". En esa atmósfera se da inicio a la sesión. El primer paso es limpiar (depilar y desinfectar) el área corporal donde se aplicará el tatuaje, luego, se transfiere la imagen escogida mediante la técnica de "calcar" y se imprimen los contornos del diseño sobre la piel. Sobre esa impresión se comienza a tatuar. El contacto aumenta, la máquina penetra el 
cuerpo, brota la sangre, la inyección de tinta continúa sobre los puntos demarcados, ocurren cambios constantes, la piel se pone roja, los trazos comienzan a aparecer y, poco a poco, el diseño gana vida en la superficie del cuerpo. Todo esto transcurre tanto en el cuerpo, en la parte física de quien es tatuado, como en su ser interior. Desde el momento en que la persona ingresa al estudio, una corriente de sensaciones comienza a fluir dentro de ella y su intensidad es cada vez mayor a medida que la aguja perfora el cuerpo y el dolor comienza a manifestarse. Una fuerte descarga emotiva acompaña así el acto de tatuarse:

—Cuando usted se sienta para tatuarse y siente la aguja entrando en su piel, ocurre una liberación de adrenalina que conduce a un estado especial [...] Un poco de esto sucede, sí, de querer sentarse, de sentir las agujas, de hacer el diseño, de pasar por aquel dolor; es un dolor que para mí no es negativo, es un dolor que me trae una satisfacción en relación con el diseño que he creado (Adriano, 32 años, enfermero, $40 \%$ del cuerpo tatuado).

-Si fuera por mí, todos los meses me haría algún tatuaje, realmente me hace falta. ¿Qué siento? Cuando se acaba, la mayor felicidad del mundo. Considero el tatuaje una terapia, algo que hace bien porque cuando tú te estás tatuando, te olvidas del mundo (Sampaio, 27 años, comerciante, $70 \%$ del cuerpo tatuado).

Como se aprecia, el acto de tatuarse provoca intensas emociones físicas y psicológicas; la adrenalina aumenta y con ella las sensaciones de felicidad, satisfacción y relajación. Al intentar comprender el sentido de esas manifestaciones emotivas ya observadas por distintos autores (Sanders, I998; Almeida, 200I; Sweetman, 1999; Le Breton, 2002), encontré una sugestiva proximidad con el concepto de flow propuesto por Cskszentmihalyi y MacAloon (I983) para explicar las experiencias ocurridas en algunos juegos y deportes, así como en el arte y en la religión, y cuyo significado Turner expresa de la siguiente manera:

Flow denota la holística sensación presente cuando el actor está en total inmersión [...] un estado en el cual se sigue la acción de acuerdo a la lógica interna, en la que parece no necesitarse conciencia por nuestra parte [...] nuestra experiencia es un fluido permanente, en cada momento, en el cual no sentimos control de nuestras acciones, y en el que casi se pierde la distinción entre nosotros mismos y el entorno; entre los estímulos y las respuestas; o entre el pasado, el presente y el futuro (Turner, I982: 55-56). 
Turner (I982) debate la competencia teórica de este concepto al afirmar que en la perspectiva de las sociedades pre-industriales, el flow actuaría más como cualidad que como patrón de conducta, mientras que en las postindustriales, donde el ritual tiene un carácter más individualista y racional, la experiencia flow está presente de forma más determinante en los géneros clasificados como: ocio, arte, deporte, juego y pasatiempo. Tales actividades, además de complejas y diversificadas, ocupan lugares importantes en la cultura como espacios de creación y desarrollo social (Turner, 1982: 58). Pese a los límites propuestos por Turner en el uso del concepto de acuerdo con el tipo de sociedad en la que se aplica, el autor resalta el valor explicativo de esa categoría, en especial, en relación con las experiencias muy emotivas vividas en distintas situaciones y contextos sociales. En este sentido, el concepto de flow es apropiado para entender el tipo de experiencia que implica el acto de tatuarse. Este concepto permite comprender algunas características importantes de esta práctica, como el hecho de que esa experiencia se encuentre en el terreno entre la acción-conciencia y la inconciencia-acción. En otras palabras, la idea de que el sujeto, a pesar de estar conciente de lo que hace, puede no estar conciente de su propia conciencia dado que su atención está enfocada en los estímulos y en las sensaciones, las cuales se convierten en determinantes de la acción (Turner, 1982). Es esta la dialéctica que viven las personas que cubren progresivamente sus cuerpos con tatuajes, grupo cada vez más numeroso y significativo para el que la sensación producida en el momento de tatuarse -llamada "adrenalina"es esencial, al punto de sentirse "invadidos" e impulsados a seguirse tatuando.

Otra característica de esa experiencia es que tiende a justificarse en sí misma, no necesita metas por fuera de ella. Por eso, es frecuente encontrar explicaciones sobre la decisión de tatuarse en las que se afirma: "Sentir, después de dos o tres meses, la falta de adrenalina funcionando en el cuerpo" (Sampaio, 2002); sensaciones que llevan a las personas a ingresar en un círculo de emotividad autocontemplativa. Tales elementos conducen a una cierta pérdida del ego, ya que durante ese estado el self comienza a desdibujarse, a ser irrelevante debido a que el actor se encuentra totalmente inmerso en la experiencia flow, y al estar en ese estado, disminuye su interés por entender, definir o dirigir cualquier acto (Turner, 1982). 
El conjunto de argumentos sobre la afectividad que se construye en esa interacción, la simbología que acompaña los distintos momentos y las fuertes emociones que allí se desencadenan, parecen indicar que el acto de tatuarse tiene características de una experiencia liminoide. Es decir, una forma de ritualidad propia de las sociedades contemporáneas que, según Turner (I982), aparece en las actividades de ocio (entendiendo el tatuaje como una actividad estética y de placer), y que pese a estar fuera de la centralidad de la vida social, contienen un importante potencial innovador: son constructoras de subjetividad.

\section{EL NUEVO PERFIL DE LOS TATUADOS}

L NUEVO SUJETO DEL TATUAJE NO PARECE TENER UN ROSTRO DEFINIDO. ES

- diverso, no tiene fronteras de género y cada vez menos de ge-neración, transita por diferentes clases sociales, tiene distintos niveles educativos, hace varias actividades, en fin, no posee un perfil social determinado. Aunque simbólicamente perdure el sentido de "gueto" que identificaba al tatuaje con los sectores marginales, rebeldes o de clase baja, en la práctica se rompieron esos límites sociales desde su ingreso al mundo del mercado convirtiéndose en una opción estético-corporal accesible a los distintos públicos. Con el propósito de entender el cambio de perfil de los usuarios del tatuaje, hice un análisis estadístico de la información disponible en la tienda de tatuaje investigada entre 1996 y 2002. ${ }^{5}$ Con base en los datos registrados en las fichas de ingreso de los clientes, pude esbozar aspectos de la tendencia actual en el uso del tatuaje, en especial, lo concerniente a las características sociales predominantes (edad y género), así como las preferencias de selección del tipo de diseño.

Como se observa en el gráfico I, es significativo el aumento de las personas pertenecientes a grupos de

5. El período analizado es relativamente corto pero representa una fase relevante para la ciudad de Florianópolis, porque durante esos años se aceleró el tránsito del tatuaje artesanal y casero al profesional. Las cifras permiten comprender el cambio de perfil de los usuarios en el nuevo escenario de esta práctica. edad más avanzados. Ese incremento, que representa el $15 \%$ de la población por encima de los 25 años y alcanza franjas etarias de más de 39 años de edad, está muy relacionado con la comercialización del tatuaje que amplió de forma notoria la oferta de 


\section{GRÁFICO I.}

DisTRIBUCIÓN DEL TATUAJE POR GRUPOS DE EDAD

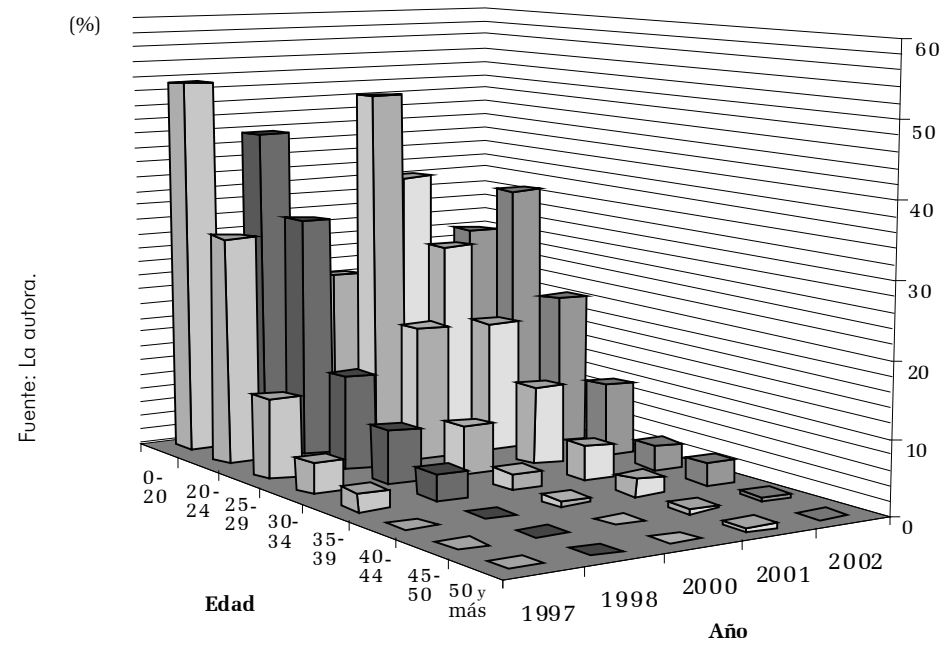

este servicio a distintos públicos. Así, los usuarios, concentrados con anterioridad en la población juvenil, ahora se distribuyen en diversos grupos de edad. Paralelo se detecta una importante reducción de los menores de edad que pasaron del 52\% del total de usuarios en I997 al 27\%, en 2002. Esta disminución progresiva estuvo determinada por la expedición de medidas de control por parte de organismos estatales que impidieron la aplicación de tatuajes en menores de edad sin la autorización de sus padres. En síntesis, la tendencia es la estabilidad en el grupo de los adultos jóvenes - entre los 20 y 30 años-, con crecimiento en las franjas etarias mayores y la disminución entre los menores de edad.

Por otra parte y como se puede observar en el gráfico 2, la correlación entre los sexos cambió radicalmente durante el periodo analizado. De un marcado predominio del sector masculino —-más del 60\%—, se pasó a la supremacía del sector femenino. ¿Qué sucedió? ¿Por qué se produjo ese cambio de perfil? Para entender esta transformación es necesario recordar que históricamente el tatuaje estaba casi restringido a los hombres y vinculado a valores culturalmente asociados con la masculinidad (coraje, agresividad, fuerza). Sin embargo, su entrada al mundo del mercado ayudó a neutralizar tales distinciones, imponiéndose el criterio universal del consumidor. El tatuaje ingresó en un proceso acelerado de “desmasculinización” que afectó profundamente la relación de género existente. En poco tiempo las mujeres no sólo 


\section{GRÁFICO 2.}

DiSTRIBUCIÓN DEL TATUAJE POR SEXOS

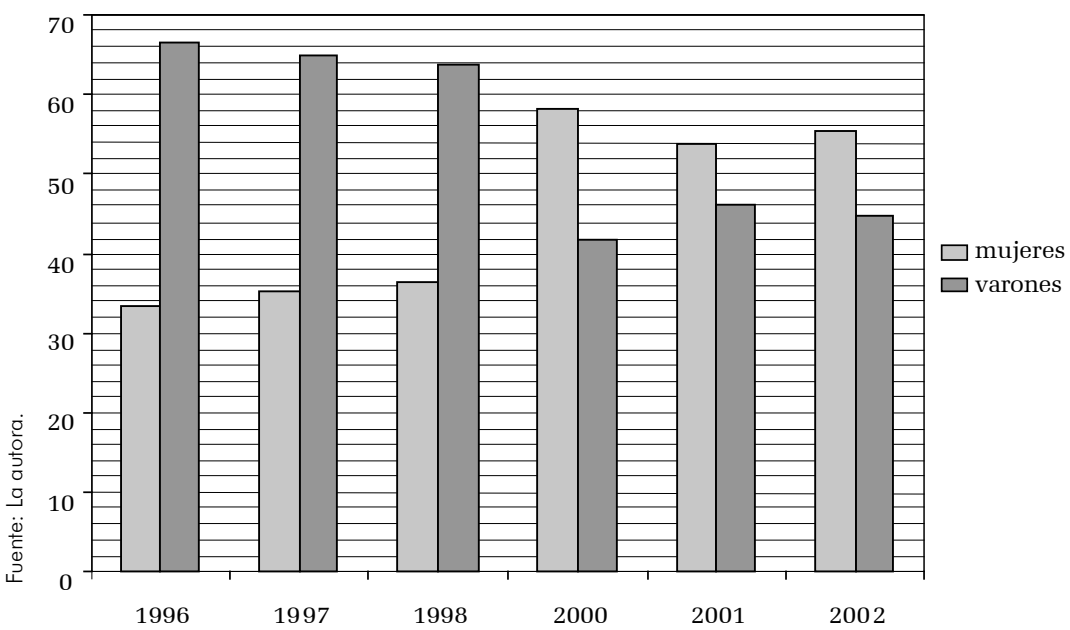

irrumpieron en ese nuevo escenario, sino que se ubicaron como primeras consumidoras. Esta tendencia no significa que se hayan eliminado las diferencias de género que se revelan en la selección del lugar del cuerpo a tatuarse y que expresan la forma como se percibe, señaliza, demarca y sexualiza cada parte del cuerpo. En el caso de las mujeres, los lugares preferidos son la parte baja de la espalda y del vientre, seguidos del cuello, la canilla y la cadera, considerados de especial connotación erótica femenina. Los hombres se inclinan primero por los brazos, la espalda y la canilla, que se relacionan con la fuerza y la virilidad, atributos dominantes de la masculinidad. La elección de los diseños también transluce las diferencias de género. En este caso, se recrea otra dimensión simbólica de la dicotomía, ya no tan ligada al erotismo, sino a las cualidades que identifican socialmente los sexos. Así, fuera de los diseños tribales ${ }^{6}$ preferidos por ambos sexos, según la muestra las mujeres se inclinan por corazones, flores, mariposas, delfines y ángeles, que representan valores

6. La preferencia por los diseños tribales, tanto en mujeres como en hombres, representa cerca del $30 \%$ de sus elecciones. Estas son imágenes inspiradas en los tatuajes de distintos pueblos aborígenes, en especial de los maorí y se caracterizan por un estilo monocromático, no figurativo, compuesto por arabescos que configuran diferentes movimientos y formas. Como afirma Célia Ramos, "son diseños que no sólo se adaptan a cualquier cuerpo sino a cualquier tiempo" (Ramos, 200I: I69); bella metáfora que ayuda a comprender su travesía a través de la historia y de las culturas, con períodos de olvido y otros de resurgimiento como ocurrió en los años 80 , cuando se pusieron de moda. 
asociados con lo femenino, lo delicado y lo tierno. Los hombres por su parte escogen indios, animales salvajes y mitológicos, calaveras, cráneos, imágenes que se relacionan con la masculinidad, la valentía, la agresividad y la fuerza. Las preferencias por los lugares y los tipos de diseño están mediadas por los universos de lo femenino y masculino, que actúan como referentes culturales o habitus de selección y que expresan una relación de género construida culturalmente y que está "inscrita hace milenios en la objetividad de las estructuras sociales y en subjetividad de las estructuras mentales" (Bourdieu, I995: 133).

\section{TATUARSE: \\ SigNificAdos Y SUBJETIVIDADES}

\section{ENTRAR EN EL TERRENO DE LA SIGNIFICACIÓN DEL TATUAJE, ES MENESTER recordar que el cuerpo ocupa un lugar central en las sociedades loccidentales. ${ }^{7}$ Es el "recinto objetivo de la soberanía del sujeto" $\mathrm{y}$, como tal, un factor fundamental en la construcción de su sub-}

7. El cuerpo comenzó a ser objeto de reflexión antropológica a partir de los estudios de la escuela francesa (Robert Hertz, I928 y Marcel Mauss, I99I), que ayudaron a entenderlo como construcción social, moldeado por las técnicas y los hábitos de cada sociedad. En esa línea de pensamiento se han desarrollado múltiples estudios teóricos y etnográficos que han ampliado el conocimiento sobre las diversas formas de concebir la corporalidad. En Brasil, el trabajo de Seeger, Da Matta e Castro (I979) marca un paso importante en esa búsqueda conceptual. Estos autores proponen las nociones de corporalidad y de persona como principios de organización social que ordenan la vida social y simbólica de las sociedades indígenas de América del Sur. En las sociedades occidentales, el cuerpo también ocupa un lugar central, sólo que en vez de "matriz de significación social" se constituye en factor de individualización. jetividad (Le Breton, 2002: I65). En tal sentido, las modificaciones corporales pueden ser entendidas como prácticas mediante las que los sujetos revelan su presencia en el mundo; son insignias de sí mismos que ayudan a afirmar su singularidad. Tatuarse es, por lo tanto, un camino de construcción de la subjetividad, de inscribir en los cuerpos algo que diferencia e identifica. Hoy en día, su significado se construye en relación con la forma en que se apropia el tatuaje y en la que entran en juego una serie de elementos como la

cantidad, los tamaños, los lugares en que se tatúan, la forma de portarlos, de exhibirlos o de esconderlos.

Así parezca difícil diferenciar, en medio de la diversidad existente, los tipos de subjetividad, es posible identificar algunas tendencias y estilos que son reconocidos por sus practicantes. Una primera clasificación construida a partir de las voces de 
los practicantes quedaría así: (a) Los de "detalle”, que emplean diseños pequeños y discretos asumidos como adornos corporales, sin generar "mayor peso o compromiso a la persona" (Mano, 2002); (b) Los "radicales" que llevan al extremo las modificaciones corporales: "Alteran su cuerpo y no hay retorno, se tatúan el rostro, se hacen implantes, escarificación, les gusta el dolor; ellos provocan un impacto muy grande ostentando lo que hacen" (Fabricio, 2002) y (c) Los "tatuados", que pese a cubrir sus cuerpos con tatuajes, mantienen formas discrecionales de uso y exhibición del tatuaje:

Nosotros llevamos una vida normal, pero nos gusta el arte, entonces, ¿qué hacemos? Llenamos nuestro cuerpo de arte, pero, donde la ropa cubra, y donde podamos exhibirnos para aquellos que merezcan vernos, para evitar ser discriminados (Gesa, 30\% del cuerpo tatuado, 2003).

Los estilos denotan un interesante juego de identificaciones y diferenciaciones y, sobre todo, la manera como sus practicantes se sitúan frente a su entorno social pues pese a las nuevas significaciones del tatuaje, este sigue siendo objeto de estigma social; según los estilos, demarca, delimita fronteras y grados de aceptación social.

LOS "TATUADOS":

CUERPOS Y ALMAS TATUADAS

ESDE MIS PRIMEROS CONTACTOS EN LA TIENDA DE TATUAJE, ME LLAMÓ LA atención un grupo de personas que, pese a estar inmersos en el mundo laboral, escolar y, en general, diversos ambientes sociales y culturales, tenían la particularidad bien marcada de estar "cerrando sus cuerpos con tatuajes". Este hecho, nada habitual en las prácticas corporales de nuestra sociedad, me despertaba muchos interrogantes, en particular cuando constaté que no eran casos aislados, sino parte de una tendencia manifiesta no sólo en individuos que estaban en procesos avanzados de "cierre corporal", sino también en aquellos jóvenes que, con apenas algunos tatuajes, ya ingresaban en esa nueva dinámica de construcción corporal. Es el caso de André, un joven que al inicio de la investigación tenía un sólo tatuaje y que al cabo de un año tenía más de tres tatuajes de tamaño considerable, además 
de varios proyectos para el futuro: "Con seguridad voy a hacerme más tatuajes, en mi pierna izquierda: una reina y otra máscara [...] y así por delante, no sé si voy a cerrar todo el cuerpo, pero sí, los brazos y las piernas" (André, estudiante, 22 anos, 2003).

Esta tendencia crea otro tipo de "normalidad" estética, sin que eso signifique que sus practicantes quieran ser excluidos o señalados como marginales. Es sólo el deseo de ser diferentes sin romper con las normas sociales, por eso, a pesar de asumir esa opción corporal, mantienen el juego de esconderse o mostrarse, según las circunstancias. En este sentido, los "tatuados" actúan de forma similar a aquellos que Goffman identifica como "desacreditables", ya que pueden jugar o, "manipular la información sobre su defecto. De exhibirlo u ocultarlo; contarlo o no contarlo; revelarlo o esconderlo; mentir o no mentir; y en cada caso para quién, cómo, cuándo y dónde" (Goffman, I985: 5I). Concientes del estigma social que aún pesa sobre el tatuaje, toman una serie de medidas de protección para evitar posibles choques sociales, entre las cuales habría que resaltar una especie de regla tácita: no tatuarse en las partes más visibles como el rostro y las manos, pues el resto del cuerpo puede ser cubierto. Es evidente que existe una tensión latente entre ser "tatuado" y ser ciudadano no excluido, ser diferente y no ser rechazado por la sociedad. Esta situación no deja de ser problemática para quienes siguen esa opción y ante lo que cabe preguntarse: ¿Por qué asumen ese tipo de modificación corporal a pesar del estigma social?

Al respecto no se podría hablar de una sola causa, sino de la convergencia de varios factores que alimentan y refuerzan esta opción. Para estas personas el acto de tatuarse tiene un significado esencial en términos de búsqueda personal; el deseo de diferenciarse, de salir de la multitud, de tener algo que los singularice: "Las personas se tatúan porque quieren un diferencial, yo no quiero ser igual a nadie y el tatuaje es mucho de eso. Yo escogí una cosa que es para siempre, que es para mí, que va más allá, que marca tu personalidad" (Luciana, 26 años, 20\% del cuerpo tatuado). Otro componente que juega un papel central en esa decisión es la parte emotiva, expresada como "sentir deseos". Es una sensación bastante fuerte, intensa, casi incontrolable que los impulsa a seguir tatuándose: "Tatuarse hace falta, se sienten ganas de tatuarse, es una necesidad casi animal...” (Gesa, 2002). Esta necesidad es conceptualizada según Almeida, como una tendencia impulsiva, difícil de controlar después del primer 
Volumen 45 (I), enero-junio 2009

tatuaje, debido a que se torna una "voluntad incontrolable que acostumbra azotar a los tatuados", que sólo se contiene por la presión social, las limitaciones en las opciones profesionales o por el temor que sienten de "acabar siendo tatuados completamente". En ese orden de ideas, la autora argumenta que se presenta una "modalidad de tentación tan fuerte que no ofrece al sujeto otra salida diferente que la ruptura física con el grupo de tatuados del cual él hace parte" (Almeida, 200I: 9).

Ahora bien, la propuesta de Almeida hay que matizarla. En primer lugar, hay que cuestionar la suficiencia del "impulso" para explicar el acto de tatuarse, ya que reducir este fenómeno a una fuerza innata, determinante de la acción humana, sería desconocer el contexto social y el conjunto de interacciones constituyentes del proceso de tatuarse. En segundo lugar, es necesario discutir ese "impulso de tatuarse" visto como "tentación" peligrosa que genera temor. Esa valoración me parece taxativa e impregnada de cierto preconcepto ante la posibilidad del "encerramiento corporal de tatuajes". ¿Puede afirmarse la ausencia de intencionalidad en la opción del tatuaje? ¿Será que tatuarse se convierte en un vicio, frente al que no queda otra alternativa que huir? Es difícil pensar en otra alternativa porque el tatuado se encuentra ante un impulso que parece no tener más explicación. No obstante, mi hipótesis es que tatuarse se convierte en una necesidad, expresada en los términos emotivos del "deseo", a partir del momento en que el sujeto se sumerge en esa práctica que afecta y transforma su ser. A través de todo lo que vive durante ese proceso, en el contacto con el tatuador, en los lazos de afectividad que se crean, en la reflexividad que se produce en torno de las búsquedas personales y en las intensas sensaciones vividas como el flow. En fin, todo lo que hace de ese acto una experiencia muy significativa. En tal dirección, cabría preguntarse si el tatuaje no se reviste de un cierto sentido religioso, en la acepción que propone Gougel de un tipo de religión personal:

La crisis cultural y religiosa de la sociedad Occidental explica, en parte, la búsqueda de un sentido más íntimo. El sujeto moderno no se reconoce más dentro de instituciones masivas como la Iglesia; él construye, cada vez más frecuentemente, una religión personal, dentro de un proceso sincrético (Gougel, 200I: I22).

Tal búsqueda de "sentido íntimo" es la que llevaría al sujeto a escoger, entre múltiples opciones, el tatuaje. Como afirma Adria- 
no: "Existen otros artificios, otras máscaras que el ser humano puede utilizar, sin embargo, para mí, el tatuaje es una realización personal importante" (2003). En este sentido, esta práctica corporal cumpliría un papel similar al de la religión, o sea, proporcionar al individuo, tal como lo observa Gougel (200I), un poco más de sentido a la dificultad de existir. Un sentido que hace del cuerpo su propio ícono. En efecto, cuando nos aproximamos al mundo de los "tatuados", el sentido de su iconografía corporal se vuelve fundamental. Con diferentes estilos — coloridos, oscuros, llenos de figuras, de rostros, de imágenes mitológicas, de formas abstractas, de seres encantados- los cuerpos de los tatuados son esculturas vivas, donde está grabado su rastro íntimo y personal. A través del tiempo, como una elaboración incesante, estos cuerpos sintetizan el proceso de construcción de sí mismos. ¿Cómo entender esa trama de imágenes? ¿Cómo descifrar los hilos de esa construcción corporal?

Al principio, creí que indagar sobre los motivos que llevaban a los "tatuados" a escoger determinadas imágenes podría ser la clave para comprender su sentido. Sin embargo, sus respuestas no parecían muy esclarecedoras: "porque me gustó", "porque la encontré bonita", "es aquella historia con la que usted, con sólo mirar, dice: iEso es lo que yo quiero!” Eran elecciones que se orientaban por criterios fundamentalmente estéticos, sin interesar la simbología implícita del diseño, así como lo confirma la bibliografía revisada (Sanders, I998; Almeida, 200I; Le Breton, 2002). ¿Qué implicaciones tiene el acto de tatuarse en términos del proceso subjetivo? ¿Son lo lúdico, el placer y la estética los únicos hilos explicativos en la construcción del sujeto? La experiencia etnográfica me indicaba que existían otros elementos para pensar el problema, de modo que comencé a profundizar en tres aspectos: el significado del gusto personal, la relación entre las imágenes escogidas y el sujeto, y el momento de la recreaciónnarración de las imágenes tatuadas.

Pese a que inicialmente el placer de los sentidos -en especial la visión - determina la elección, es necesario tener en cuenta que en este acto no sólo prevalece una sensación agradable, sino que también existe una fijación en algo, en una determinada idea. Esa focalización en una idea es lo que posibilita establecer un nexo con el sujeto, un referente de sentido, ligado a las emociones, a la experiencia sensible, a aspectos que no son vacíos de significado y que permiten elaborar un reconocimiento de 
sí mismos y de su entorno social. Como lo afirma Berger (I972), las imágenes están cargadas de sentido, tanto personal como social, sólo que se expresan en otro lenguaje, el visual, donde se pone en juego "el modo de ver" el mundo, implícito en toda representación. Por eso, para entender el significado del repertorio de las imágenes escogidas por los "tatuados" es necesario pensar en el lenguaje moderno del tatuaje, más que en el contenido representativo de las imágenes como se hacía antes. Eso nos lleva a poner de relieve la dimensión artística de la imagen sin desconocer el proceso de construcción de sentido sobre dichas imágenes, pues el tatuaje tiene un patrimonio iconográfico común (reproducido por los catálogos, las revistas, las páginas de internet) que actúa como base de referencia. Cada persona, además, recrea ese simbolismo con sus propios criterios y formas de interpretación del mundo.

Otro ángulo que ayuda a entender el proceso de significación del tatuaje es el momento en que la persona "narra" el sentido de sus tatuajes. La narración abre una nueva dimensión de introspección del sujeto pues aunque él sabe que le "gusta" su tatuaje, también necesita incluirlo en su universo de significaciones y responder a la mirada de los otros que observan e indagan. El tatuaje no pasa inadvertido, es visible y objeto de especulaciones, por eso es necesario traducirlo, crear una metáfora en torno de él, simple o compleja, que tenga valor comunicativo. En ese acto se produce una revelación subjetiva: El encuentro de sentido(s), de vínculos que salen a la superficie, de asociaciones que permiten identificar facetas de sí mismo, de la relevancia y el lugar de esa experiencia en su vida. Así, pese a ser una expresión individual, el tatuaje está delimitado por lo social e incluso puede afirmarse que el sentido de tatuarse se construye en función de la relación con los otros. Por un lado, la relación con el tatuador, quien participa en las búsquedas subjetivas de la persona con los referentes familiares y el entorno social que soporta su mundo imaginario y con el mundo externo que trae consigo la mirada indagadora. Por otro, las redes sociales formadas por los amantes de este arte y que constituyen, tal como lo señala Mafessoli (1998), grupos abiertos, fluidos, informales, unidos alrededor del disfrute del momento y de la experiencia estética. Sus encuentros, pese a ser espontáneos y efímeros, están cargados de afectividad y de evocaciones comunes en torno de sus vivencias e intereses por el tatuaje, tema central de sus conversaciones que configura una 
especie de "laboratorio", donde intercambian opiniones, socializan sus propuestas y recrean sus proyectos corporales.

Por último, falta analizar el fenómeno del tatuaje progresivo, que implica ir más allá del tatuaje en su singularidad y entender el conjunto: La forma en que la trama de imágenes, disgregadas por sus cuerpos, comienza a cubrir toda su piel. Al respecto, hay que tener en cuenta que esa dinámica corporal carece de parámetros; cada persona se tatúa a su ritmo, con su propio estilo, en distintas escalas y proporciones. Es, en síntesis, una construcción iconográfica totalmente personal y original. Tal autarquía iconográfica no está exenta de polémicas. Por ejemplo, Grognard afirma que los tatuados se convierten en una especie de espectáculo de circo por la falta de criterios en la elección de los diseños y, sobre todo, por la manera en que distribuyen y enlazan las distintas imágenes, sin ningún orden temático, a merced de cualquier imaginación, dando como resultado final: "Una creación extravagante” (Grognard, 1992: 29). En efecto, los "tatuados” no se guían por ningún orden estético convencional; ellos rompen con la normatividad artística, recrean en sus cuerpos una nueva perspectiva de construcción estética corporal. En este aspecto son muy subversivos e innovadores porque confrontan los modelos de cuerpo (natural) y de estética (clásica) dominantes socialmente. Pero esto no significa que carezcan de juicio estético, sus criterios obedecen a un lenguaje simbólico en construcción, en experimentación, y su laboratorio de prueba es su cuerpo. De hecho, la noción de experimentación parece bastante apropiada para hablar de ese proceso de cubrimiento corporal en el que, con el paso del tiempo, la mayoría de sus actores realizan sensibles cambios en la forma, el estilo y la perspectiva de tatuarse. Cuando comienzan a tatuarse no prestan mucha atención a la calidad técnica de los diseños que realizan ni tampoco su localización corporal o la articulación entre ellos. Sin embargo, en la medida en que se sumergen en el medio y adquieren mayor dominio de ese lenguaje corporal, desarrollan una nueva mirada que los lleva a replantear muchos de los diseños realizados y los retocan, recubren o enlazan.

Así, en el transcurso de ese proceso vivencial, de aproximaciones, de pruebas, de ensayos y de interacciones con los demás actores, surge la noción de proyecto corporal, que es fundamental en este contexto porque genera nuevos sentidos y, sobre todo, da 
una "orientación" a esa dinámica progresiva de tatuarse. Hacerse un tatuaje deja de ser un acto aislado y pasa a connotar un movimiento cuyo escenario es todo el cuerpo; un cuerpo pensado como unidad, en términos de composición y armonía, donde los diseños ingresan a una dinámica que los articula con metas y planes futuros.

Quiero hacerme más tatuajes, pero ahora no haría uno sólo, sino un miembro entero, el antebrazo, la pierna, no quiero hacerme diseños sueltos ni de álbumes, quiero una cosa diseñada por un artista y que yo me identifique (Fabricio, 25 años, 30\% del cuerpo tatuado, 2002).

El tatuaje progresivo puede pensarse entonces como una construcción, tanto en el sentido de proyecto, que engloba las expectativas y planes de los "tatuados", como en el sentido retrospectivo, en la reconstrucción de sus historias personales. De modo que, además de las ideas futuras que corporifican permanentemente, sus cuerpos se transforman en álbumes donde está inscrita la memoria de sus vivencias, de sus referencias afectivas, de sus deseos y experiencias; en fin, un mosaico representativo de su propio imaginario, que "marca" su presencia en el mundo.

\section{Conclusiones}

N ESTA INVESTIGACIÓN SE PRIVILEGIÓ LA PERSPECTIVA DE LA PRÁCTICA, - entendida como un "mundo social en construcción" (Ortner, 1994) donde las relaciones, las experiencias, los procesos y los sujetos cumplen un papel determinante. Con base en este enfoque, se intentó abarcar las distintas dimensiones que entran en juego durante el proceso de tatuarse, tales como: (a) El nuevo imaginario social que enaltece el valor del cuerpo y de la estética, y en el que tratan de situarse los modernos estudios de tatuaje; (b) El mundo afectivo creado alrededor de esa práctica; (c) Las fuertes experiencias emotivas que se desencadenan en este acto, produciendo un estado de ritualidad contemporánea (Turner, 1982); y (d) Las búsquedas personales — de diferenciación, de sentido íntimo, de placer-, que hacen del tatuaje una opción corporal y de vida. Opción que a pesar de ser subversiva en relación con la concepción tradicional del cuerpo, como un 
hecho "natural e inalterable", también es una subversión pacífica y de alguna manera viabilizada por el nuevo orden de las cosas, donde el cuerpo ocupa un lugar central dentro de la cultura contemporánea (Le Breton, 1995; 2002).

Otro aspecto importante de resaltar en este estudio es el tipo de subjetividad que se configura en la actualidad con el uso y la apropiación del tatuaje. Según la información recogida, se puede hablar de tres estilos principales: el de los sujetos que se hacen "tatuajes de detalle" que no generan compromiso social, los "radicales" que llevan al extremo las modificaciones corporales y los "tatuados" que se caracterizan por estar en un proceso de "cubrimiento corporal" y se mantienen dentro de las convenciones sociales. Los "tatuados", grupo en el que profundicé, ingresan a un "proyecto de construcción corporal y de vida" forjado a partir de aspectos como el contacto íntimo con el tatuador que se convierte en una especie de mediador no sólo de su proceso de construcción corporal sino de su propia subjetividad, la relación con el grupo de los "tatuados" con quienes construyen lazos de afectividad que refuerzan sus "proyectos" en torno del tatuaje, la experiencia flow, sensación intensa que actúa como estimulante del acto de tatuarse, la construcción de una iconografía personal mediante la que el sujeto fabrica su cuerpo y en su cuerpo, a sí mismo; y finalmente la creación de un "imaginario personal" elaborado a partir del proceso de construcción corporal y que se constituye en una importante vía de autoafirmación.

Por último, me gustaría enfatizar en el debate en torno de la naturaleza del acto, en apariencia compulsivo, de continuar tatuándose y que lleva a algunos autores como Almeida (2002) a plantear que esa subjetividad obedece sólo a impulsos emotivos que valen como pura estetización de la vida. Si bien es cierto que la decisión de tatuarse está muy vinculada con el mundo emotivo, esto no significa que se carezca de momentos reflexivos significativos como el esclarecimiento de las "ideas del tatuaje", en el que mediante la visibilización de los gustos y las preferencias de los sujetos, se accede a su mundo interno. O también cuando luego de realizado el tatuaje, la persona verbaliza ese acto y da lugar a revelaciones y descubrimientos de sí misma. En este sentido, es cuestionable la fragmentación del sujeto en universos dicotómicos como el emotivo-estético versus reflexivo-profundo que limitan la comprensión de este fenómeno. Propongo entonces tener en cuenta las múltiples dimensiones que entran en juego 
en esta práctica y que hacen del tatuaje hoy un escenario de construcción subjetiva abierto, fluido, constituido en la interfase entre las búsquedas individuales y los procesos de interacción social, entre el disfrute estético y la formación de sentido íntimo, entre el ser interno reflexivo y los impulsos emocionales, como un movimiento dialéctico e innovador.

\section{Bibliografía}

Almeida, Maria Isabel. 200I. "Tatuagem e Subjetividade: Reflexões em torno do Imaginário da Epiderme”. Interseções, Revista de Estudos Interdisciplinares. No. I.

Berger, John. 1972. Modos de Ver. Martins Fontes. Sao Paulo.

BOURDIEu, PierRe. I995. "A Dominação Masculina”. Educação e Realidade. 20: (2).

Douglas, Mary. I973. Pureza y Peligro. Siglo XXI. Madrid.

FALK, PASI. 1995. "Written in the Flesh". Body \& Society. I: (I).

Goffman, Erving. 1985. Estigma. Zahar. Río de Janeiro.

Gougel D’allondans, Thierry. 200I. "Le Tatouage, entre Lien et Séparation". Historie et Anthropologie. 23.

Grognard, Catherine. I992. Tatouages. Tags à l'âme. Syros Alternatives. París.

HerTz, RoBert. 1928. “La prééminence de la main droit”. En Mélanges de sociologie religieuse et de folklore. Librairie Félix Alcan. París.

Le Breton, David. I995. Antropología del Cuerpo y Modernidad. Nueva Visión. Buenos Aires.

2002. Signes D'identité. Tatouages, Piercings et Autres Marques Corporelles. Métailié. París.

MacAllon, J. y Csikszentminayi, M. (1983). "Deep Play and the Flow Experience in Rock climbing”. En Harris, J. y Park, R (ed.). Play, Games and Sports in Cultural Contexts. Human Kinetics Publishers. Champaign. Illinois.

Maffesoli, Michel. 1998. O tempo das tribos. Forense Universitária. Río de Janeiro. 
Marques, Toni. 1997. O Brasil Tatuado e Outros Mundos. Rocco. Río de Janeiro.

Mauss, Marcel. I99I. “Las Técnicas Corporales”. En Sociología y Antropología. Tecnos. Madrid.

Ortner, Sherry. I994. “Theory in Anthropology Since the Sixties”. En Culture, Power, History: A Reader in Contemporary Social Theory. N. B. Dirks, G. Eley y S. Ortner (eds.). Princeton University Press.

Pierrat, Jeronne. 2000. Les Hommes Illustrés. Le Tatouage des Origines a Nos Jours. Larivière. París.

Ramos, Célia. 200I. Teorias da Tatuagem. Corpo Tatuado. UDESC. Florianópolis.

Sanders, Clinton. I998. "Marks of Mischief. Becoming and Being Tattooed”. Journal of Contemporary Ethnography. 16: (4).

Seeger, A; Da Matta, R; Viveiros De Castro, E. i979. "A Construção da Pessoa nas Sociedades indígenas Brasileiras”. Boletim do Museu Nacional. 32.

Sweetman, Paul. 1999. "Only Skin Deep? Tattooing, Piercing and the Transgressive Body”. En M. Aaron (ed.). The Body's Perilous Pleasures. Edinburgh University Press.

Turner, Victor. I982. "Liminal to Liminoid. in Play, Flow, and Ritual: An Essay in Comparative Symbology". En V. Turner From Ritual to Theatre. The Human Seriousness of Play. PAJ. Nueva York. 